Article

\title{
The Microstructure Evolution, Mechanical Properties and Densification Mechanism of TiAl-Based Alloys Prepared by Spark Plasma Sintering
}

\author{
Dongjun Wang ${ }^{1,2, *}$, Hao Yuan ${ }^{3}$ and Jianming Qiang ${ }^{3}$ \\ 1 National Key Laboratory for Precision Hot Processing of Metals, Harbin Institute of Technology, \\ Harbin 150001, China \\ 2 Key Laboratory of Micro-Systems and Micro-Structures Manufacturing, Ministry of Education, \\ Harbin 150001, China \\ 3 School of Materials Science and Engineering, Harbin Institute of Technology, Harbin 150001, China; \\ yh18345168977@gmail.com (H.Y.); q2564108815@gmail.com (J.Q.) \\ * Correspondence: dongjunwang@hit.edu.cn; Tel.: +86-451-8640-2590; Fax: +86-451-8641-8714
}

Academic Editor: Mark T. Whittaker

Received: 27 April 2017; Accepted: 26 May 2017; Published: 2 June 2017

\begin{abstract}
The microstructure evolution and mechanical properties of a Ti-Al-Cr-Nb alloy prepared by spark plasma sintering (SPS) at different temperatures and stresses were investigated in detail. Sintering temperature plays a key role in the densification process and phase transformation, which determines the microstructure. The mechanical properties of the sintered alloys depend on the microstructure caused by the sintering. Furthermore, the densification process and mechanism of TiAl-based metallic powders during SPS were studied based on experimental results and theoretical analysis, the results of which will help fabricate these kinds of intermetallic alloys using a powder metallurgy technique and accelerate their industrial applications.
\end{abstract}

Keywords: intermetallics; aerospace; powder metallurgy; microstructure evolution; mechanical property; densification

\section{Introduction}

Alloys based on the intermetallic phase $\gamma$-TiAl are increasingly used as potential replacements for nickel-based superalloys in different application fields, e.g., turbine blades, space vehicles, and stationary turbines [1,2]. TiAl-based alloys have attracted this attention due to their low density (about $4 \mathrm{~g} / \mathrm{cm}^{3}$ ), high yield strength at high temperature, good oxidation resistance, and corrosion resistance $[3,4]$.

TiAl-based alloys can usually be produced by conventional casting or ingot metallurgy, etc. However, microstructural defects such as porosity, coarse grain and composition heterogeneity, and low material utilization ratio of TiAl-based alloys hinder their actual engineering applications. The mechanical properties of TiAl-based alloys mainly depend on their microstructure [5,6], and thus the alloys are regularly forcibly treated using hot isostatic processing (HIP), or hot processing $[7,8]$ to eliminate porosity or refine grains, which can improve their performance, but inversely gives rise to a longer manufacturing duration and higher cost of investment.

In recent years, powder metallurgy (PM) has been considered as an alternative processing technique for the preparation of TiAl-based alloys as the near-net-shape forming method $[9,10]$. Furthermore, TiAl-based metallic powders with fine grains and homogeneous composition can be obtained during a gas atomization process. Afterwards, the atomized powders usually consolidate into bulk by hot pressing, or the HIP method [11]. Particularly, spark plasma sintering (SPS) can 
satisfactorily compact powders through high intensity pulsed direct current and stress, and it is currently attracting the attention of the industrial field due to its advantages such as rapidity, cheapness, and simplicity [12-14]. Lin et al. [15] fabricated a high Nb-containing Ti-45Al-8.5Nb-(W, B, Y) alloy using the SPS and HIP methods. Couret et al. [16] obtained a near-lamellar Ti-48Al-2W-0.02B alloy and the effects of $B$ addition were investigated. Liu et al. [17] conducted spark plasma sintering of a beta phase-containing Ti-44Al-3Nb-1Mo-1V-0.2Y alloy with potentially good hot deformability. To fabricate TiAl-based alloys with considerable properties through the PM route, it is necessary to carry out a densification process by which the alloys with high density are obtained. Moreover, the sintering parameters can affect the phase morphology and thus influence the mechanical properties. To attempt the near-net fabrication of TiAl alloys and parts utilized at a temperature of $\sim 800{ }^{\circ} \mathrm{C}$, it was of importance to understand the relationship between the sintering process, densification, microstructure, and properties of TiAl-based alloys during sintering, which can provide and supply more information about this alloy using the PM technique.

In this paper, based on the study of the microstructure evolution and mechanical properties of TiAl-based alloys prepared by SPS, the effect of parameters on the densification process was analyzed, leading to a more basic understanding of intermetallic alloys for fabrication using the PM technique.

\section{Materials and Methods}

Gas atomized TiAl powders (Ti-46.5Al-2.15Cr-1.90 Nb, atomic percent) with sizes between 20 and $80 \mu \mathrm{m}$ were prepared and sintered using 3.20-MK-V SPS equipment for $7 \mathrm{~min}$ at different temperatures $\left(900,1050,1100,1150\right.$, and $\left.1250{ }^{\circ} \mathrm{C}\right)$ under a pressure of $50 \mathrm{MPa}$. For comparison, more samples were sintered under pressures of 10 and $30 \mathrm{MPa}$ at $1150{ }^{\circ} \mathrm{C}$, as well as under pressure of $50 \mathrm{MPa}$ at $1000{ }^{\circ} \mathrm{C}$. The sintering temperatures were measured with a pyrometer on the external surface of the graphite molds. The pressure and temperature started simultaneously at the time of zero and the pressure was kept constant during sintering. The heating rate was initially $120 \mathrm{~K} / \mathrm{min}$, and was reduced to $20 \mathrm{~K} / \mathrm{min}$ for the last $100 \mathrm{~K}$ to mitigate temperature overshooting. The temperatures given in this paper were the monitored temperatures. After holding at the sintering temperature, the heating current and the pressure were released, followed by sample cooling in the SPS chamber. Two typical samples were fabricated with cylindrical shapes of $\Phi 20 \mathrm{~mm} \times 10 \mathrm{~mm}$ and $\Phi 45 \mathrm{~mm} \times 15 \mathrm{~mm}$, respectively. The structural characteristics were investigated by $\mathrm{X}$-ray diffraction $(\mathrm{XRD}, \mathrm{D} / \mathrm{Max}-\mathrm{RA}$ diffractometer (Rigaku Corporation, Tokyo, Japan), operated with $\mathrm{Cu} \mathrm{K \alpha}$ ), differential thermal analysis (DTA, NETZSCH STA 449C, NETZSCH company, Selb, Germany), and scanning electron microscopy (SEM, Quanta200FEG, FEI company, Hillsboro, OR, USA), equipped with energy dispersive spectroscopy (EDS, FEI company, Hillsboro, OR, USA). For the SEM analysis, the back-scattered electron (BSE) detector (FEI company, Hillsboro, OR, USA) was used. The densities of the sintered samples were determined using the "Archimedes" method. Micro-hardness was measured using a Matsuzawa SeikiMHT-1 micro-hardness tester ((MATSUZAWA SEIKI Co. LTD, Tokyo, Japan) under a load of $50 \mathrm{~g}$. The mechanical responses with a dimension of $\Phi 3 \mathrm{~mm} \times 4.5 \mathrm{~mm}$ (aspect ratio of 1.5) were evaluated by the quasi-static compression test at room temperature with a strain rate of $5 \times 10^{-4} \mathrm{~s}^{-1}$. The two sides of each specimen were carefully ground and polished until they were parallel to each other in order to mitigate the effect of friction during tests. The fracture surfaces of the samples were also examined by SEM (secondary electron detector).

\section{Results and Discussion}

\subsection{Microstructure Evolution}

Figure 1 shows the XRD patterns of the TiAl powders and the samples sintered at different temperatures. For the atomized powders, they were mainly composed of a single $\alpha_{2}$ phase due to the rapid cooling rate. Similar phase constitution has been reported in small size TiAl powders prepared by gas atomization in Reference [18]. These results also suggested that the atomized powders 
were in a non-equilibrium state caused by rapid solidification. The diffraction patterns of samples after sintering were similar. As can be seen, the sharp diffraction peaks belonging to TiAl and $\mathrm{Ti}_{3} \mathrm{Al}$ confirmed that the TiAl-based alloys after SPS contained substantive amounts of $\gamma$ (e.g., dark phase in Figure 2D,E), and $\alpha_{2}$ phases (e.g., bright phase in Figure 2D,E). Moreover, the bulk TiAl-based alloy with a dimension of $\Phi 45 \mathrm{~mm} \times 15 \mathrm{~mm}$ and cylinder-shaped part with the dimension of $\Phi 30$ (internal diameter 10) $\mathrm{mm} \times 30 \mathrm{~mm}$ prepared by SPS are shown in the inset of Figure 1. One can see that the spark plasma sintered TiAl-based alloy exhibited a shining metallic luster in appearance.

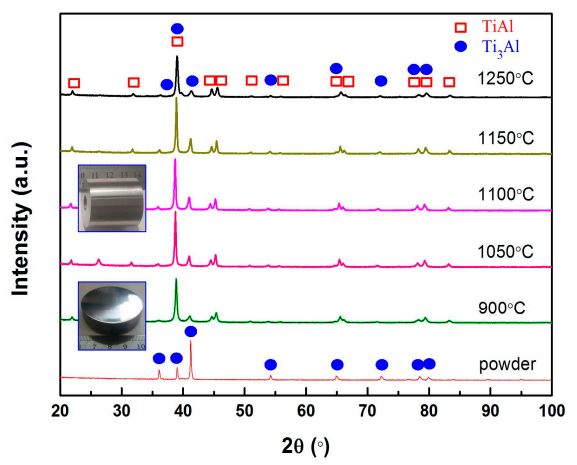

Figure 1. X-ray diffraction patterns of the samples.

The SEM observations of the powders and samples sintered at different temperatures are shown in Figure 2. As can be seen, the powder exhibited a dendritic-like microstructure containing a large amount of out-of-equilibrium $\alpha_{2}$ phase (Figure 2A). Based on EDS analysis, the composition of metallic powders was $\mathrm{Ti}_{50.46} \mathrm{Al}_{45.61} \mathrm{Cr}_{1.99} \mathrm{Nb}_{1.94}($ at $\%)$, which was close to the nominal composition of this alloy.

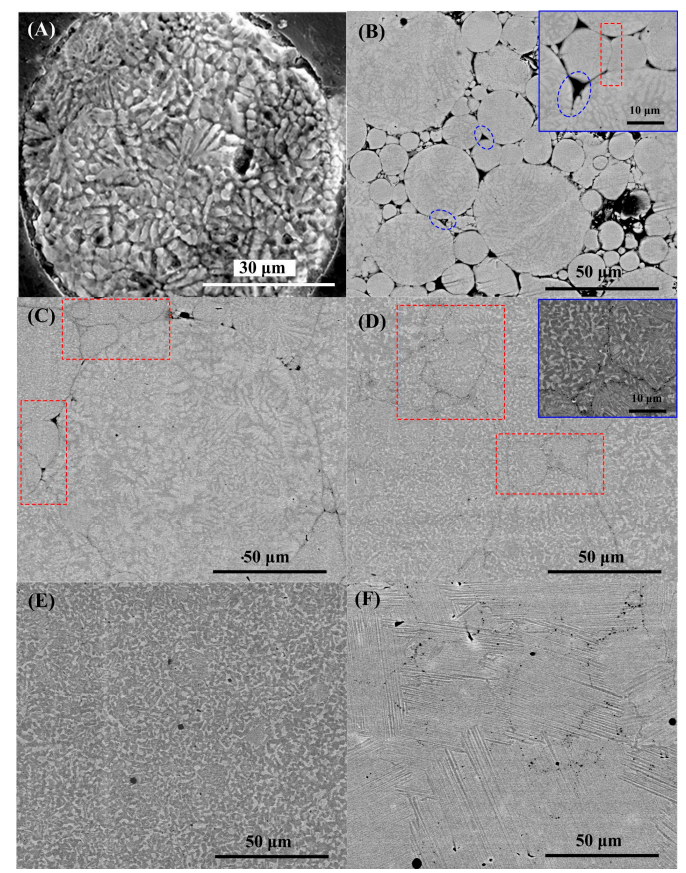

Figure 2. Scanning electron microscopy (SEM) images of the atomized powder (A) and the sintered samples at (B) $900{ }^{\circ} \mathrm{C}$; (C) $1050{ }^{\circ} \mathrm{C}$; (D) $1100^{\circ} \mathrm{C}$; (E) $1150{ }^{\circ} \mathrm{C}$; and (F) $1250{ }^{\circ} \mathrm{C}$.

For the sample consolidated at $900{ }^{\circ} \mathrm{C}$, the microstructure had significant porosity, especially at triple contact areas of powder particles (blue dashed region of Figure 2B). It was also noted that the plastic deformation of some small powders occurred at this temperature (red dashed region of inset of 
Figure 2B), suggesting that densification initially took place. When the sintering temperature increased to $1050{ }^{\circ} \mathrm{C}$ (Figure 2C), a few pores could still be seen, although a more compact microstructure was obtained. Moreover, more deformed features of small powders were observed (red dashed region in Figure 2C). With an increase in temperature to $1100{ }^{\circ} \mathrm{C}$ (Figure 2D), macroscopic pores disappeared post-sintering. However, the grain boundaries (GBs) were still visible at the contact areas among the deformed powders (e.g., red dashed region), which indicates that plastic deformation plays a key role in the densification process. In addition, compared with the alloys at lower sintering temperatures (Figure 2B,C), the non-equilibrium dendritic microstructure (Figure 2A) of the powders disappeared for the sample sintered at $1100{ }^{\circ} \mathrm{C}$ (inset of Figure 2D). With further increases in temperature (Figure 2E), one could see a highly dense microstructure of the alloy sintered at $1150{ }^{\circ} \mathrm{C}$ without GBs observed, revealing a high sintering density and sufficient densification at this temperature. It is also of importance to note that a double-phase microstructure was obtained. From a chemical composition perspective, the composition of the bright $\alpha_{2}$ phase was $\mathrm{Ti}_{53.98} \mathrm{Al}_{41.85} \mathrm{Cr}_{2.24} \mathrm{Nb}_{1.94}$ (at \%, relatively rich in $\mathrm{Ti}$ ), and that of the dark $\gamma$ phase was $\mathrm{Ti}_{47.48} \mathrm{Al}_{48.76} \mathrm{Cr}_{1.90} \mathrm{Nb}_{1.86}$ (at \%, relatively rich in $\mathrm{Al}$ ). Aside from the compact microstructure, the sample sintered at $1250{ }^{\circ} \mathrm{C}$ exhibited lamella morphology (Figure $2 \mathrm{~F}$ ). As shown, this lamella microstructure contained homogeneous lamellar colonies $\alpha_{2} / \gamma$. Moreover, the composition of these lamellas was $\operatorname{Ti}_{49.63} \mathrm{Al}_{46.40} \mathrm{Cr}_{2.15} \mathrm{Nb}_{1.82}$ (at \%) based on EDS, which is close to the nominal composition of this alloy.

To verify the phase transformation point of TiAl-based powders, a DTA analysis was conducted, and the experimental curve is shown in Figure 3. In this curve, two endothermal peaks based on phase transformation were observed. Based on this, the eutectoid temperature $\left(T_{e}\right)$ and the $\alpha$ transus temperature $\left(T_{\alpha}\right)$ of the powders were estimated to be approximately 1260 and $1315^{\circ} \mathrm{C}$, respectively. During the SPS, the temperature can induce phase transformation and thus affect the microstructure and densification. For a given experiment, the actual temperature could even be $160{ }^{\circ} \mathrm{C}$ higher than the monitored SPS temperature [19]. When the sintering temperature was $1150^{\circ} \mathrm{C}$, it was deduced that the actual temperature of the powders could be higher than $1260^{\circ} \mathrm{C}\left(T_{e}\right)$. In this case, the sample was composed of $\gamma$ phase and $\alpha$ phase ( $\alpha+\gamma$ phase region) at this sintering temperature. Upon cooling, the $\alpha$ phase transformed into an ordered $\alpha_{2}$ phase, while the $\gamma$ phase remained and a double-phase microstructure formed for the sintered sample (Figure 2E). When the powders were sintered at $1250{ }^{\circ} \mathrm{C}$, the actual temperature could be above $T_{\alpha}$, thus the microstructure consisted of $\alpha$ grains in this situation. During cooling, the formation of a lamellar microstructure (Figure 2F) took place following the evolution of $\alpha \rightarrow \alpha+\gamma \rightarrow \alpha_{2}+\gamma$. Meanwhile, it was also of interest to note that the dendritic-like microstructure of rapid atomized powders was not seen after densification. To understand this, it is well documented that recrystallization can occur dynamically during densification of the powders [12]. Since a clear tendency to recrystallize can occur in the deformed zones [20], the deformation of metallic powders (Figure 2B-D) during densification will result in recrystallization, and in turn an equilibrium microstructure, due to a large amount of stored deformation energy.

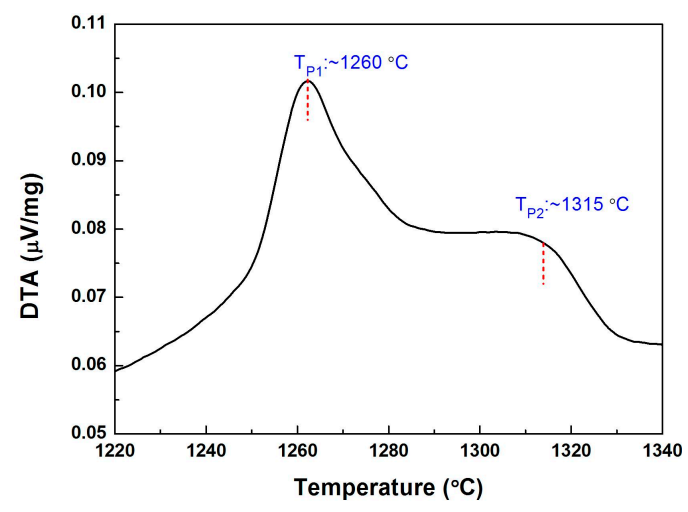

Figure 3. Differential thermal analysis curve of the powder sample. 


\subsection{Mechanical Property}

The density and micro-hardness of the samples sintered at different temperatures were investigated and are shown in Table 1 . One can clearly see that the density and hardness of the sample with a lower sintering temperature exhibited relatively smaller values due to numerous pores after sintering, e.g., $900{ }^{\circ} \mathrm{C}$. When the sintering temperature increased to $1050,1100,1150$, and $1250{ }^{\circ} \mathrm{C}$, the density increased sharply and then nearly kept at constant. Furthermore, the hardness of the samples sintered at higher temperatures was also similar, which indicates that hardness is mainly dependent on density.

Table 1. Mechanical properties of TiAl-based alloys sintered at different temperatures.

\begin{tabular}{cccccc}
\hline Temperature $\left({ }^{\circ} \mathbf{C}\right)$ & $\mathbf{9 0 0}$ & $\mathbf{1 0 5 0}$ & $\mathbf{1 1 0 0}$ & $\mathbf{1 1 5 0}$ & $\mathbf{1 2 5 0}$ \\
\hline Density $\left(\mathrm{g} / \mathrm{cm}^{3}\right)$ & 3.392 & 3.944 & 3.966 & 3.967 & 3.965 \\
Hardness $(\mathrm{HV})$ & 278.6 & 413.0 & 420.0 & 417.0 & 430.0 \\
\hline
\end{tabular}

The relationship between fracture true strength, plastic strain, and sintering temperature is shown in Figure 4, as are the true stress-true strain curves of the sintered samples. When the sintering temperature was low $\left(900^{\circ} \mathrm{C}\right)$, the sample broke with no plastic strain and a very low fracture strength of $\sim 350 \mathrm{MPa}$. Many pores in this sample (Figure 2B) resulted in its weak compressive response. When the sintering temperature rose to 1050 and $1100{ }^{\circ} \mathrm{C}$, the densification process gradually took place and more compact microstructures were achieved (Figure 2C,D). Therefore, the mechanical performances of these two samples were significantly improved compared with samples sintered at lower temperatures, e.g., the fracture true strength and plastic strain of the samples sintered at 1050 and $1100{ }^{\circ} \mathrm{C}$ were $1795 \mathrm{MPa}$ and $24.8 \%$, and $1754 \mathrm{MPa}$ and $26.2 \%$, respectively. As shown, the sample sintered at $1150{ }^{\circ} \mathrm{C}$ with high density (Figure 2E) had optimal compressive properties at room temperature. The fracture true strength was $1820 \mathrm{MPa}$ and the plastic true strain could also be as high as $32.6 \%$. Although the density was like that of the sample sintered at $1150{ }^{\circ} \mathrm{C}$, both the fracture strength and the plastic strain of the sample sintered at $1250{ }^{\circ} \mathrm{C}$ dramatically decreased. Based on the above composition results, it was noted that the change of composition before and after sintering was slight, suggesting that a homogeneous composition was obtained during SPS. Further to composition, it is well known that the mechanical properties of alloys are determined by the microstructure, namely the synergetic effect of density and phase transformation for the sintered TiAl-based alloys. For the sample sintered at $1150{ }^{\circ} \mathrm{C}$, the high strength and considerable plasticity was attributed to the high density and small grain size. However, the poor strength and limited plasticity of the lamellar microstructure $\left(1250^{\circ} \mathrm{C}\right)$ was caused by the lack of texture [19]. Therefore, the dislocations could propagate more easily and thus initiate the crack, which eventually led to the rapid failure of the sample. It can be concluded from the abovementioned results that the temperature of SPS has two main roles: (1) giving rise to densification; (2) changing the microstructure through phase transformation. Thus, to improve the mechanical properties of TiAl-based alloys, the PM technique can provide a simplified route, i.e., the combined processing for fabrication and microstructural optimization for the required composition. 


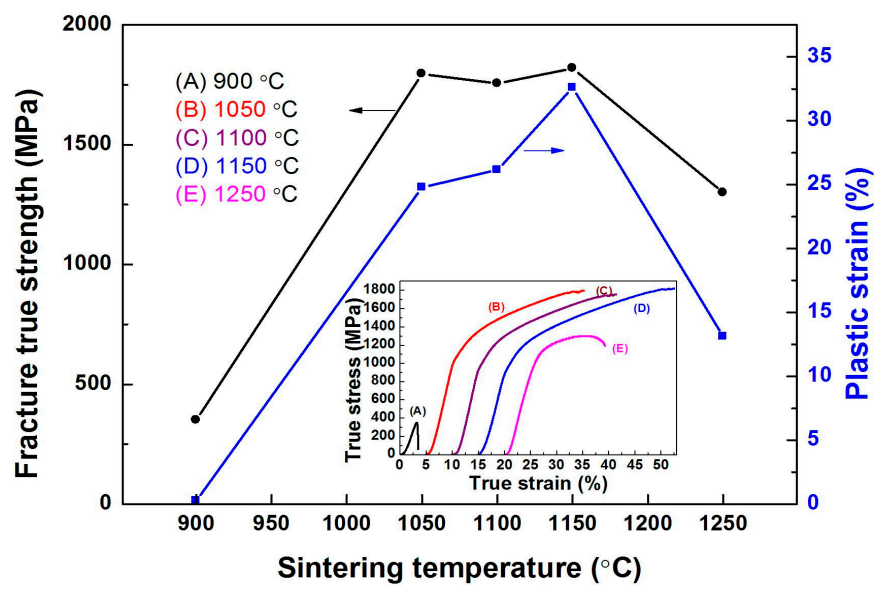

Figure 4. Room temperature compressive properties of the sintered TiAl alloys. The true stress-strain curves have been off-set for better visualization.

The typical fracture morphologies of the sintered samples are presented in Figure 5. Based on Figure 5A, one can see melt-like features at the triple junctions of powder particles, suggesting that spark plasma sintering promotes integration among the contact areas of the particles. Nevertheless, it was evident that a few globate powder particles were removed from the surface by external loading, which agrees with the high porosity and poor mechanical properties of the sample sintered at $900{ }^{\circ} \mathrm{C}$ (Figure $2 \mathrm{~B}$ and Table 1). For the sample sintered at $1150{ }^{\circ} \mathrm{C}$ (Figure 5B), intergranular fracture characteristics were observed. This fracture morphology was like that of the as-cast TiAl-based alloys, indicating its high density and good mechanical properties. When the sintering temperature increased to $1250{ }^{\circ} \mathrm{C}$, cracks were seen on the fracture surface. In particular, the lamella-like imprints dominated the fracture morphology and further confirmed the lamellar microstructure of the sample sintered at this temperature.

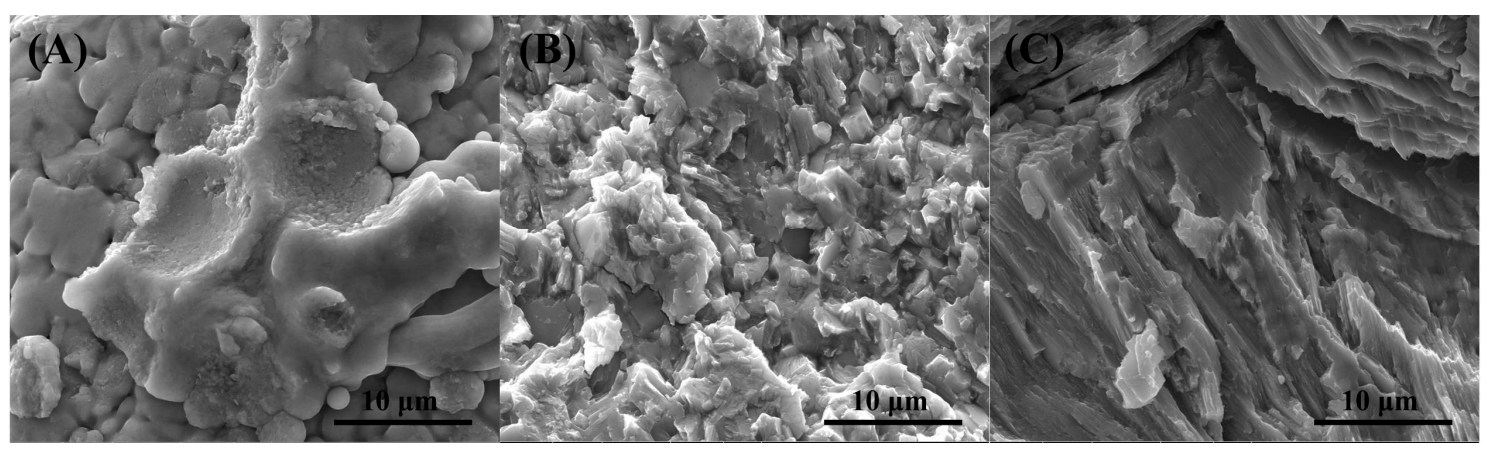

Figure 5. Fracture morphologies of the sintered samples: (A) $900{ }^{\circ} \mathrm{C}$; (B) $1150{ }^{\circ} \mathrm{C}$; (C) $1250{ }^{\circ} \mathrm{C}$.

\subsection{Densification Process}

To better understand the effect of sintering parameters on the densification of TiAl-based metallic powders during SPS, a model suggested by Bernard-Granger and Guizard [21] was used to analyze the sintering process. In this model, the flow stress for high-temperature deformation of the alloy is described as a function of strain rate $(\dot{\varepsilon})$ and temperature $(T)$ by Equation (1) [22].

$$
\dot{\varepsilon}=\frac{\mathrm{d} \varepsilon}{\mathrm{d} t}=\mathrm{A} \frac{D G_{0} b}{k T}\left(\frac{b}{d}\right)^{p}\left(\frac{\sigma}{G_{0}}\right)^{n}
$$


where $\dot{\varepsilon}$ is the strain rate; A is the constant; $D$ is the diffusion coefficient; $G_{0}$ is the shear modulus; $b$ is the Burgers vector; $k$ is Boltzmann's constant; $T$ is temperature; $d$ is grain size; $\sigma$ is the macroscopic applied stress; $p$ is the inverse grain size exponent; $n$ is the stress exponent; and $t$ is time.

During sintering, the strain rate is compared to the densification rate as per Equation (2) [23].

$$
\dot{\varepsilon}=\frac{1}{\rho} \frac{\mathrm{d} \rho}{\mathrm{d} t}
$$

where $\rho$ is the density. By taking the integral transformation of Equation (2), one can obtain Equation (3):

$$
\varepsilon=\ln \rho
$$

As per Equations (1)-(3), there are three main factors that determine the densification $(\rho)$ during sintering: the diffusion coefficient $D$, the temperature $T$, and the applied stress $\sigma$. It is well documented that the diffusion coefficient $D$ is mainly dominated by temperature; namely, the higher the temperature, the larger the diffusion coefficient. Therefore, when the temperature rises, the macroscopic sintering density increases and is maintained at nearly constant (Table 1).

In addition, based on the experimental data, the relationships between temperature, punch displacement, and sintering time were recorded, and a typical result of the sample sintered at $1150{ }^{\circ} \mathrm{C}$ is shown in Figure 6. During SPS, sintering can be divided into different stages to analyze the densification $[24,25]$. As shown in Figure 6, there were two clear sintering stages in our study, namely curve A-B and curve B-C-D for the displacement data. For the first stage (curve A-B), the punch displacement decreased due to the powder thermal expansion caused by the increase in temperature. The second stage (curve B-C-D) was important for densification, and the density increased sharply in accordance with the increase in temperature and punch displacement.

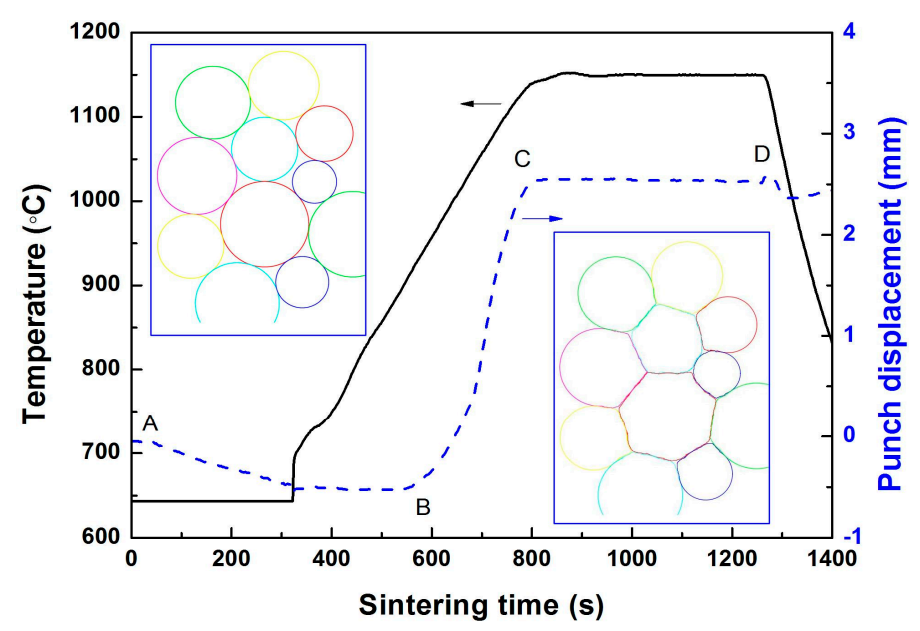

Figure 6. Temperature and punch displacement curves versus time for sintering at $1150{ }^{\circ} \mathrm{C}$.

It was noted that sintering involved several mechanisms microscopically operating simultaneously over these stages. Plastic deformation, e.g., in the form of dislocation movement, can play a role in densification [26]. During sintering, the loose powders initially encounter each other through the combined effect of temperature and sintering stress (upper left inset of Figure 6). When sintered at $900{ }^{\circ} \mathrm{C}$, the particles were in contact and were forced to deform, followed by the formation of sintering necks (inset of Figure 2B). Due to the applied pressure, densification took place through the plastic deformation of the powder particles and the dislocation emitted atoms as it moved close to the neck. However, this densification was not sufficient, and many large pores were visible (Figure 2B). In particular, the pores at the contacts of the powder particles exhibited sharp cusps (blue dashed region of Figure 2B) at this temperature. It is well known that the vacancy concentration that can act as 
an atomic diffusion path under a curved surface, depends on the curvature of the two perpendicular radii of curvature for the surface. Based on the two-sphere sintering model, the particle surface is convex and the sintering bond is concave, thus there will be a vacancy concentration gradient between these two [27]. Moreover, the solid surface energy-due to a concave curvature at the neck-also generates capillary stress as a driving force for atom diffusion. Therefore, the result is that vacancy flows away from the neck and atomic diffusion moves into the neck, resulting in the blunting of sharp cusps for the pores. Nevertheless, the pore cusps for the sample sintered at $900{ }^{\circ} \mathrm{C}$ (blue dashed region of Figure 2B) suggested that the diffusion mechanism played a minor role during this initial stage of densification and the deformation was considered as a dominant mechanism in this stage. By increasing the sintering temperature $\left(1050-1100^{\circ} \mathrm{C}\right)$, densification could be further associated with more plastic deformation of the particles (red dashed regions in Figure 2C,D) due to lower yield stress with increased temperatures. It was obvious that some small rounded powders deformed into elliptic shapes or even irregular shapes to fill the vacancies. The plastic deformation led to the flattening of contact areas and the reduction of porosity (Figure 2C,D), as demonstrated in the lower right inset of Figure 6. For the sample sintered at $1150{ }^{\circ} \mathrm{C}$ (Figure 2E), sufficient densification occurred and a nearly full dense microstructure was obtained.

In contrast, at the areas of the powder contacts during SPS there was current through the powder particles. Coupled with the plastic deformation discussed above, electro-thermal and heat transfer can occur at the contact interface when axial pressure applied. It is well known that motion such as thermal diffusion caused by heat transfer can promote mass transfer driven by Gibbs-Thomson driving forces [20], which is also responsible for interface bonding and causes densification from a microscopic perspective. After neck formation through deformation in the initial stage $\left(900{ }^{\circ} \mathrm{C}\right)$, the grain boundaries formed within the neck (Figures 7a and 2B-D) between individual particles as random grain contacts led to misaligned crystals [28]. When the sintering temperature (such as $1000^{\circ} \mathrm{C}$ ) increased, the diffusion mechanism significantly affected densification in comparison with lower temperatures. The evident sharp cusps (Figure 2B) of the pores were blunted and the pore structure became rounded (Figure $7 \mathrm{~b}$ ). In addition, blunted neck morphology between adjacent particles was observed and typical results are shown in the red dashed regions in Figure $7 \mathrm{~b}$. Similar neck features were also seen in the samples sintered at 1050 and $1100{ }^{\circ} \mathrm{C}$. Based on the above discussions, our results indicate that the diffusion mechanism occurred at a relatively higher temperature and the atoms diffusion (caused by capillary stress due to concave curvature) was performed to remove this curvature gradient. During diffusion, the collaborated mass moved from the solid particle to deposit on the pores, i.e., the atoms moved along the particle surfaces (surface diffusion), along grain boundaries (grain boundary diffusion), and through the lattice interior (volume diffusion). A schematic illustration of the microscopic diffusion paths and interface bonding during the densification of TiAl powders is shown in Figure 7a. Although the surface diffusion produced neck growth, it did not lead to a change in particle spacing [29], that is, no densification occurred since the mass flow originated and terminated at the particle surface. Densification took place only by bulk transport, as the mass responsible for growing the sintering neck comes from inside the powder particles, for example, from grain boundary diffusion and volume diffusion [30]. As seen in Figure 7a, the crystalline solid powders joined at the interparticle neck with a misalignment of crystal planes, resulting in a grain boundary where defective atomic bonding enabled rapid atomic diffusion and thus contributed to the densification [31]. Furthermore, effective volume diffusion involved the motion of vacancies along the lattice paths and a counter flow of atoms into the pores, which required relatively higher activation energy. Compared with volume diffusion activated at higher temperatures, there existed a sufficient grain boundary area due to the small particle size of this work (Figures 2B-D and $7 \mathrm{~b}$ ). Therefore, the grain boundary diffusion was considered as the dominant diffusion densification mechanism. Based on the above analysis, the sintering necks would form and gradually grow among adjacent particles through the synergetic mechanism of deformation and thermal diffusion. Thus, the pores were filled and the microstructure became compacted. 


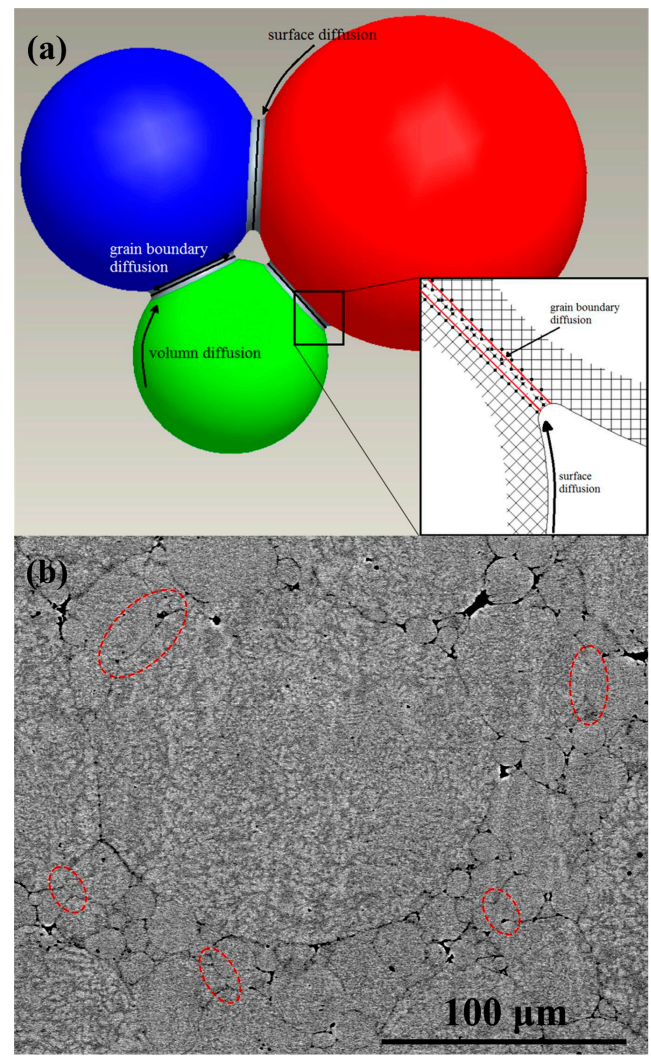

Figure 7. Schematic illustration of diffusion paths and interface bonding during spark plasma sintering (SPS) densification of TiAl powders (a); and the microstructure of the sample sintered at $1000{ }^{\circ} \mathrm{C}(\mathbf{b})$.

Besides temperature, it was also noted from Equations (1)-(3) that the applied stress could affect densification. To verify the influence of sintering stress, more samples were sintered at $1150{ }^{\circ} \mathrm{C}$ under different applied stresses, as shown in Table 2. As seen, a higher sintering density was obtained by applying larger sintering stress. Thus, the imposition of higher sintering pressure on powder-powder interfaces led to more severe deformation and accelerated the mass transport of the particles, which could promote the densification as per the abovementioned discussions.

Table 2. Sintering densities of TiAl-based alloys under different stresses at $1150{ }^{\circ} \mathrm{C}$.

\begin{tabular}{cccc}
\hline Stress $\mathbf{( M P a})$ & $\mathbf{1 0}$ & $\mathbf{3 0}$ & $\mathbf{5 0}$ \\
\hline Density $\left(\mathrm{g} / \mathrm{cm}^{3}\right)$ & 3.947 & 3.961 & 3.967 \\
\hline
\end{tabular}

\section{Conclusions}

Sintering temperature mainly determines the densification and phase transformation of TiAl-based metallic powders during SPS. By increasing the temperature, the density of sintered alloys increased and then stayed nearly constant. For the alloys sintered at 1150 and $1250{ }^{\circ} \mathrm{C}$, the microstructures exhibited double-phase and lamellar characteristics, respectively, due to the phase transformation, despite having similar densities. The mechanical properties of the sintered alloys depended on the microstructures caused by sintering conditions, such as porosity and phase morphology. At lower temperatures and stress, the micro-hardness, fracture strength, and plastic strain increased with the increase in density. For alloys with similar densities sintered at a high temperature and stress, the phase morphology affected the mechanical properties. In this work, the alloy sintered at $1150{ }^{\circ} \mathrm{C}$ with a double-phase microstructure showed optimal properties for a fracture true strength of $1820 \mathrm{MPa}$ and a plastic true strain of $32.6 \%$ at a room-temperature compressive test. Thus, sintering 
parameters including temperature and pressure can influence the densification process and a high density can be achieved through sufficient plastic deformation and thermal diffusion, such as the grain boundary diffusion of metallic powders caused by the effect of temperature and pressure.

Acknowledgments: This work is financially supported by the National Natural Science Foundation of China (No. 51674093), the Natural Science Foundation of Heilongjiang Province (No. E201425), the Fundamental Research Funds for the Central Universities (No. HIT.KLOF.2013021 and HIT.MKSTISP.2016019), and the Postdoctoral Scientific Research Development Fund of Heilongjiang Province (No. LBH-Q15040).

Author Contributions: Dongjun Wang conceived and designed the experiments. Hao Yuan and Jianming Qiang searched literatures. Hao Yuan performed the experiments and collected the data. Hao Yuan and Jianming Qiang interpreted the data. Dongjun Wang analyzed the data and wrote the paper.

Conflicts of Interest: The authors declare no conflict of interest.

\section{References}

1. Lagos, M.A.; Agote, I. SPS synthesis and consolidation of TiAl alloys from elemental powder: Microstructure evolution. Intermetallics 2013, 36, 51-56. [CrossRef]

2. Liss, K.D.; Funakoshi, K.I.; Dippenaar, R.J.; Higo, Y.; Shiro, A.; Reid, M.; Suzuki, H.; Shobu, T.; Akita, K. Hydrostatic compression behavior and high-pressure stabilized $\beta$-phase in $\gamma$-based titanium aluminide intermetallics. Metals 2016, 6, 165. [CrossRef]

3. Liu, H.W.; Rong, R.; Gao, F.; Li, Z.X.; Liu, Y.G.; Wang, Q.F. Hot deformation behavior and microstructural evolution characteristics of Ti-44Al-5V-1Cr alloy containing $\left(\gamma+\alpha_{2}+\right.$ B2) phases. Metals 2016, 6, 305. [CrossRef]

4. Clemens, H.; Mayer, S. Design, processing, microstructure, and applications of advanced intermetallic TiAl alloys. Adv. Eng. Mater. 2013, 15, 191-215. [CrossRef]

5. Niu, H.Z.; Chen, Y.Y.; Xiao, S.L.; Xu, L.J. Microstructure evolution and mechanical properties of a novel beta $\gamma$-TiAl alloy. Intermetallics 2012, 31, 225-231. [CrossRef]

6. Edalati, K.; Toh, S.; Iwaoka, H.; Watanabe, M.; Horita, Z.; Kashioka, D.; Kishida, K.; Inui, H. Ultrahigh strength and high plasticity in TiAl intermetallics with bimodal grain structure and nanotwins. Scr. Mater. 2012, 67, 814-817. [CrossRef]

7. Miriyev, A.; Levy, A.; Kalabukhov, S.; Frage, N. Interface evolution and shear strength of Al/Ti bi-metals processed by a spark plasma sintering (SPS) apparatus. J. Alloy Compd. 2016, 678, 329-336. [CrossRef]

8. Sadeghi, E.; Karimzadeh, F.; Abbasi, M.H. Thermodynamic analysis of Ti-Al-C intermetallics formation by mechanical alloying. J. Alloy Compd. 2013, 576, 317-323. [CrossRef]

9. Guillaume, B.G.; Chrisian, G. Spark plasma sintering of a commercially available granulated zirconia powder: I. Sintering path and hypotheses about the mechanism(s) controlling densification. Acta Mater. 2007, 55, 3493-3504.

10. Jiang, D.T.; Hulbert, D.M.; Kuntz, J.D.; Anselmi-Tamburini, U.; Mukherjee, A.K. Spark plasma sintering: A high strain rate low temperature forming tool for ceramics. Mater. Sci. Eng. A 2013, 463, 89-93. [CrossRef]

11. Li, J.; Liu, Y.; Liu, B.; Wang, Y.; Liang, X.; He, Y. Microstructure characterization and mechanical behaviors of a hot forged high $\mathrm{Nb}$ containing PM TiAl alloy. Mater. Charact. 2014, 95, 148-156. [CrossRef]

12. Trzaska, Z.; Couret, A.; Monchoux, J.P. Spark plasma sintering mechanisms at the necks between TiAl powder particles. Acta Mater. 2016, 118, 100-108. [CrossRef]

13. Ghasali, E.; Pakseresht, A.H.; Alizadeh, M.; Shirvanimoghaddam, K.; Ebadzadeh, T. Vanadium carbide reinforced aluminum matrix composite prepared by conventional, microwave and spark plasma sintering. J. Alloy Compd. 2016, 688, 527-533. [CrossRef]

14. Shirvanimoghaddam, K.; Hamim, S.U.; Akbari, M.K.; Fakhrhoseini, S.M.; Khayyam, H.; Pakseresht, A.H.; Ghasali, E.; Zabet, M.; Munir, K.S.; Jia, S.; et al. Carbon fiber reinforced metal matrix composites: Fabrication process and properties. Composites Part A 2017, 92, 70-96. [CrossRef]

15. Wang, Y.H.; Lin, J.P.; He, Y.H.; Wang, Y.L.; Chen, G.L. Microstructures and mechanical properties of Ti-45Al-8.5Nb-(W, B, Y) alloy by SPS-HIP route. Mater. Sci. Eng. A 2008, 489, 55-61. [CrossRef]

16. Voisin, T.; Monchoux, J.P.; Perrut, M.; Couret, A. Obtaining of a fine near-lamellar microstructure in TiAl alloys by spark plasma sintering. Intermetallics 2016, 71, 88-97. [CrossRef] 
17. Liu, X.W.; Zhang, Z.L.; Sun, R.; Liu, F.C.; Fan, Z.T.; Niu, H.Z. Microstructure and mechanical properties of beta TiAl alloys elaborated by spark plasma sintering. Intermetallics 2014, 55, 177-183. [CrossRef]

18. Wang, Y.H.; Lin, J.P.; He, Y.H.; Wang, Y.L.; Chen, G.L. Fabrication and SPS microstructure of Ti-45Al-8.5Nb(W, B, Y) alloying powders. Intermetallics 2008, 16, 215-224. [CrossRef]

19. Couret, A.; Molenat, G.; Galy, J.; Thomas, M. Microstructures and mechanical properties of TiAl alloys consolidated by spark plasma sintering. Intermetallics 2008, 16, 1134-1141. [CrossRef]

20. Jabbar, H.; Couret, A.; Durand, L.; Monchoux, J.P. Identification of microstructural mechanisms during densification of a TiAl alloy by spark plasma sintering. J. Alloy Compd. 2011, 509, 9826-9835. [CrossRef]

21. Lee, G.; Yurlova, M.S.; Giuntini, D.; Grigoryev, E.G.; Khasanov, O.L.; Mckittrick, J.; Olevsky, E.A. Densification of zirconium nitride by spark plasma sintering and high voltage electric discharge consolidation: A comparative analysis. Ceram. Int. 2015, 41, 14973-14987. [CrossRef]

22. Niraj, C.; Koundinya, N.T.B.N.; Srivastav, A.K.; Kottada, R.S. On correlation between densification kinetics during spark plasma sintering and compressive creep of B2 aluminides. Scr. Mater. 2015, 107, 63-66.

23. Lodhe, M.; Chawake, N.; Yadav, D.; Balasubramanian, M. On correlation between $\beta \rightarrow \alpha$ transformation and densification mechanisms in SiC during spark plasma sintering. Scr. Mater. 2016, 115, 137-140. [CrossRef]

24. Voisin, T.; Durand, L.; Karnatak, N.; Gallet, S.L.; Thomas, M.; Berre, Y.L.; Castagné, J.F.; Couret, A. Temperature control during spark plasma sintering and application to up-scaling and complex shaping. J. Mater. Process. Technol. 2013, 213, 269-278. [CrossRef]

25. Ghasali, E.; Shirvanimoghaddam, K.; Pakseresht, A.H.; Alizadeh, M.; Ebadzadeh, T. Evaluation of microstructure and mechanical properties of $\mathrm{Al}-\mathrm{TaC}$ composites prepared by spark plasma sintering process. J. Alloy Compd. 2017, 705, 283-289. [CrossRef]

26. Wang, J.W.; Wang, Y.; Liu, Y.; Li, J.B.; He, L.Z.; Zhang, C. Densification and microstructural evolution of a high niobium containing TiAl alloy consolidated by spark plasma sintering. Intermetallics 2015, 64, 70-77. [CrossRef]

27. German, R. Sintering from Empirical Observations to Scientific Principles, 1st ed.; Butterworth-Heinemann: Oxford, UK, 2014; pp. 197-198.

28. Zhang, W.; Gladwell, I. Sintering of two particles by surface and grain boundary diffusion-A three dimensional model and numerical study. Comp. Mater. Sci. 1998, 12, 84-104. [CrossRef]

29. Wang, J.C. Analysis of early stage sintering with simultaneous surface and volume diffusion. Metall. Mater. Trans. A 1990, 21, 305-312. [CrossRef]

30. Chng, H.N.; Pan, J. Cubic spline elements for modeling microstructural evolution of materials controlled by solid-state diffusion and grain boundary migration. J. Comp. Phys. 2004, 196, 724-750. [CrossRef]

31. Svoboda, J.; Riedel, H. Quasi-equilibrium sintering for coupled grain boundary and surface diffusion. Acta Metall. Mater. 1995, 43, 499-506. [CrossRef]

(C) 2017 by the authors. Licensee MDPI, Basel, Switzerland. This article is an open access article distributed under the terms and conditions of the Creative Commons Attribution (CC BY) license (http://creativecommons.org/licenses/by/4.0/). 